\title{
Variable TERRA abundance and stability in cervical cancer cells
}

\author{
BONG-KYEONG OH ${ }^{1}$, PONNARATH KEO $^{1}$, JAEMAN BAE $^{1,2}$, JUNG HWA KO $^{3}$ and JOONG SUB CHOI ${ }^{1,2}$ \\ ${ }^{1}$ Institute of Medical Science, Hanyang University College of Medicine, Seoul 133-791; \\ ${ }^{2}$ Division of Gynecologic Oncology and Gynecologic Minimally Invasive Surgery, Department of Obstetrics and Gynecology, \\ Hanyang University College of Medicine, Seoul 133-791; ${ }^{3}$ Department of Obstetrics and Gynecology, \\ Hallym University Kangdong Sacred Heart Hospital, Seoul 05355, Republic of Korea
}

Received March 18, 2016; Accepted March 31, 2017

DOI: $10.3892 /$ ijmm.2017.2956

\begin{abstract}
Telomeres are transcribed into long non-coding RNA, referred to as telomeric repeat-containing RNA (TERRA), which plays important roles in maintaining telomere integrity and heterochromatin formation. TERRA has been well characterized in HeLa cells, a type of cervical cancer cell. However, TERRA abundance and stability have not been examined in other cervical cancer cells, at least to the best of our knowledge. Thus, in this study, we measured TERRA levels and stability, as well as telomere length in 6 cervical cancer cell lines, HeLa, SiHa, CaSki, HeLa S3, C-33A and SNU-17. We also examined the association between the TERRA level and its stability and telomere length. We found that the TERRA level was several fold greater in the SiHa, CaSki, HeLa S3, C-33A and SNU-17 cells, than in the HeLa cells. An RNA stability assay of actinomycin D-treated cells revealed that TERRA had a short half-life of $\sim 4 \mathrm{~h}$ in HeLa cells, which was consistent with previous studies, but was more stable with a longer half-life $(>8 \mathrm{~h})$ in the other 5 cell lines. Telomere length varied from 4 to $9 \mathrm{~kb}$ in the cells and did not correlate significantly with the TERRA level. On the whole, our data indicate that TERRA abundance and stability vary between different types of cervical cancer cells. TERRA degrades rapidly in HeLa cells, but is maintained stably in other cervical cancer cells that accumulate higher levels of TERRA. TERRA abundance is associated with the stability of RNA in cervical cancer cells, but is unlikely associated with telomere length.
\end{abstract}

\section{Introduction}

Telomeres protect chromosomal ends from replicative attrition $(1,2)$. The maintenance of telomere length and structure is

Correspondence to: Dr Joong Sub Choi, Division of Gynecologic Oncology and Gynecologic Minimally Invasive Surgery, Department of Obstetrics and Gynecology, Hanyang University College of Medicine, 222 Wangsimni-ro, Seongdong-gu, Seoul 133-791, Republic of Korea

E-mail: choiyjjy1@hanyang.ac.kr

Key words: cervical cancer cells, telomeric repeat-containing RNA, telomere critical to preserving telomere integrity. The majority of human cancer cells maintain telomere length via the activation of telomerase, which allows unlimited cell growth (3). Telomerase reverse transcriptase (TERT) is a rate-limiting component of telomerase that is expressed only in telomerase-positive cells $(4,5)$. Telomere DNA, tandem (TTAGGG)n repeats, is tightly associated with specialized telomeric protein complexes, termed shelterin (6).

Telomeres are transcribed from the subtelomere toward the telomere into heterogeneous long non-coding RNA, which are referred to as telomeric repeat-containing RNA or TERRA $(7,8)$. TERRA is found in most eukaryotes (9-11), and its transcription is carried out primarily by RNA polymerase II (RNAPII) in humans and yeasts $(8,9,11,12)$. As with other RNAPII-mediated transcription, transcriptional activity is repressed by telomere heterochromatin regulation $(12,13)$. Human TERRA has a short half-life and a cap structure at its 5'-end, and a small fraction of TERRA is polyadenylated at its 3'-end; polyadenylation is known to increase TERRA stability (14). TERRA accumulates in highly proliferating cancer cells, and elevated TERRA levels are found in various types of human cancer (15). However, whether elevated TERRA levels result from changes in transcriptional activity or increased stability of the RNA remains poorly understood.

TERRA is involved in various processes, such as telomere protection, telomere replication and the epigenetic state of telomere chromatin (16). However, the effects of telomere length on TERRA transcription remain controversial. A correlation between TERRA upregulation and short telomeres has been found in patients with immunodeficiency, centromeric instability and facial anomalies syndrome (17). The induction of TERRA transcription at a specific chromosome leads to telomere shortening of that chromosome (18). TERRA mimicking RNA oligonucleotide acts as a telomerase inhibitor (19). Moreover, cancer cells exhibit decreased TERRA levels upon telomere elongation mediated by telomerase overexpression (13). Taken together, the data from these studies suggest that telomere length is related to TERRA expression in a negative manner. By contrast, telomere overelongation does not cause marked differences in TERRA abundance in Saccharomyces cerevisiae (20), which has also been observed in primary human lung fibroblasts and $\mathrm{HeLa}$ cells (21). Moreover, a lack of correlation between these two parameters has been reported in human cell lines (22). Thus, further studies are warranted to explore the functional effects of telomere length on TERRA expression. 
TERRA is well characterized in HeLa, a cervical cancer cell line, as a model cell line (14). However, TERRA stability and abundance have not been examined in other cervical cancer cells, at least to the best of our knowledge. Thus, in this study, we measured TERRA level and stability, as well as telomere length in 6 human cervical cancer cells and examined whether TERRA abundance is related to stability and telomere length. We found that TERRA was more stable in cells with high levels of TERRA, but that telomere length is unlikely to be associated with TERRA expression in cervical cancer cells.

\section{Materials and methods}

Cell culture. The cells were grown in Dulbecco's modified Eagle's medium or RPMI-1640 supplemented with $10 \%$ fetal bovine serum (both from Wellgene, Seoul, Korea), $100 \mu \mathrm{g} / \mathrm{ml}$ of streptomycin, and $100 \mathrm{U} / \mathrm{ml}$ of penicillin (Gibco, Carlsbad, CA, USA). The SiHa, CaSki, HeLa, HeLa S3 and SNU-17 cells were purchased from the Korean Cell Line Bank (KCLB, Seoul, Korea), and C-33A was generously provided by the Yonsei Cancer Center, Seoul, Korea.

Slot-blot analysis of TERRA. Total RNA was isolated from the cells using TRIzol ${ }^{\circledR}$ reagent (Invitrogen, Carlsbad, CA, USA) or Tri-RNA (Favorgen, Koahsiung, Taiwan) according to the manufacturer's instructions. Total RNA was diluted to $0.02 \mu \mathrm{g} / \mu \mathrm{l}$, and 20,100 or $200 \mu \mathrm{l}$ of the RNA dilution was immobilized onto a nylon membrane (Hybond ${ }^{\mathrm{TM}} \mathrm{N}+$; Amersham Biosciences, Piscataway, NJ, USA) for the detection of TERRA. Similarly, 10, 50 or $100 \mu \mathrm{l}$ of RNA dilution at a concentration of $0.004 \mu \mathrm{g} / \mu \mathrm{l}$ was loaded for the detection of $18 \mathrm{~S}$ rRNA. After UV cross-linking (Stratagene, La Jolla, CA, USA), the filters were hybridized with either a 3'-end DIG-labeled oligonucleotide d(CCCTAA) $)_{4}$ or a DIG-randomlabeled $18 \mathrm{~S}$ rDNA probe overnight at $45^{\circ} \mathrm{C}$, and detection was performed using a detection starter kit (Roche, Mannheim, Germany). The blot hybridized with DIG-d(CCCTAA) was erased in $50 \%$ formamide, $5 \%$ sodium dodecyl sulfate and $50 \mathrm{mM}$ Tris- $\mathrm{HCl}, \mathrm{pH} 7.4$ at $60^{\circ} \mathrm{C}$, for $60 \mathrm{~min}$ twice, and reprobed with DIG-d(TTAGGG) $)_{4}$. DIG-labeled d(CCCTAA) and d(TTAGGG) $)_{4}$, and DIG-random-labeled 18S rDNA probes were generated using terminal transferase and DIG-High Prime (both from Roche), respectively. For the TERRA stability assay, total RNA was isolated from the cells treated with actinomycin D (Act D; Sigma, St. Louis, MO, USA) at $5 \mu \mathrm{g} / \mathrm{ml}$ for the times indicated in the figures, and slot blotting was performed as described above.

Reverse transcription-quantitative-polymerase chain reaction $(R T-q P C R)$. cDNA was generated using M-MLV reverse transcriptase (Invitrogen). cDNA synthesis was performed with $1.0 \mu \mathrm{g}$ of total RNA in a total volume of $20 \mu \mathrm{l}$ according to the manufacturer's instructions (Invitrogen). The reaction was incubated at $37^{\circ} \mathrm{C}$ for $50 \mathrm{~min}$ and then terminated at $70^{\circ} \mathrm{C}$ for $15 \mathrm{~min}$ for specific primers or at $25^{\circ} \mathrm{C}$ for $10 \mathrm{~min}, 37^{\circ} \mathrm{C}$ for $50 \mathrm{~min}$, and $70^{\circ} \mathrm{C}$ for $15 \mathrm{~min}$ for random primers (Takara, Kyoto, Japan). The primers used for reverse transcription are as follows: 5'-AGTCCGCCTAGAAGCATTTG-3' for $\beta$-actin (14), and 5'-CCCTAACCCTAACCCTAACCCTAACCCTAA-3' for TERRA (14).PCR reactions were performed in $10 \mu \mathrm{l}$ containing
Table I. Oligonucleotides used for RT-qPCR.

\begin{tabular}{|c|c|c|}
\hline Transcript & Primers sequences $\left(5^{\prime} \rightarrow 3^{\prime}\right)$ & Refs. \\
\hline $10 \mathrm{q}-$ & F:GAATCCTGCGCACCGAGAT & (13) \\
\hline TERRA & R:CTGCACTTGAACCCTGCAATAC & (13) \\
\hline $13 q-$ & F:GCACTTGAACCCTGCAATACAG & (24) \\
\hline TERRA & R:CCTGCGCACCGAGATTCT & (24) \\
\hline $15 \mathrm{q}-$ & F:CAGCGAGATTCTCCCAAGCTAAG & (14) \\
\hline TERRA & R:AACCCTAACCACATGAGCAACG & (14) \\
\hline $16 \mathrm{p}-$ & F:TGCAACCGGGAAAGATTTTATT & (24) \\
\hline TERRA & R:GCCTGGCTTTGGGACAACT & (24) \\
\hline $17 q-$ & F:AGCTACСТCTCTCAACACCAAGAAG & (24) \\
\hline TERRA & R:GTCCATGCATTCTCCATTGATAAG & (24) \\
\hline $\mathrm{XqYq-}$ & F:CCCCTTGCCTTGGGAGAA & (24) \\
\hline TERRA & R:GAAAGCAAAAGCCCCTCTGA & (24) \\
\hline XpYp- & F:GCAAAGAGTGAAAGAACGAAGCTT & (14) \\
\hline TERRA & R:CCCTCTGAAAGTGGACCAATCA & (14) \\
\hline \multirow[t]{2}{*}{ TERT } & F:CTGGAACCATAGCGTCAGGG & This study \\
\hline & R:ACAGAAACCACGGTCACTCG & This study \\
\hline \multirow[t]{2}{*}{ PinX1 } & F:CACTCCAGAGGAGAACGAAACC & This study \\
\hline & R:CACCGGCTTGGCAAAGTACT & This study \\
\hline \multirow[t]{2}{*}{ TRF1 } & F:TGCTTTCAGTGGCTCTTCTG & $(34)$ \\
\hline & R:ATGGAACCCAGCAACAAGAC & (34) \\
\hline \multirow[t]{2}{*}{ TRF2 } & F:TTGTGGGGTCCTTGGACATA & (34) \\
\hline & R:CCAGTAGAAAACTGGTCAAGGAA & (34) \\
\hline \multirow[t]{2}{*}{$\beta$-actin } & F:TGTACGCCAACACAGTGCTG & (13) \\
\hline & R:GCTGGAAGGTGGACAGCG & (13) \\
\hline \multirow[t]{2}{*}{ snU1 } & F:GGCGAGGCTTATCCATTG & (14) \\
\hline & R:CCCACTACCACAAATTATGC & (14) \\
\hline
\end{tabular}

TERRA, telomeric repeat-containing RNA; TRF1, telomere repeat-binding factor 1 ; $\mathrm{F}$, forward; $\mathrm{R}$, reverse.

1X SYBR ${ }^{\circledR}$-Green PCR master mix (Roche), $0.2 \mu \mathrm{M}$ of each forward and reverse primer (Table I) and $1.0 \mu \mathrm{l}$ of cDNA. The negative control included nuclease-free water instead of cDNA. PCR was performed with a LightCycler ${ }^{\circledR} 480$ Sequence Detection system (Roche) under the following conditions: denaturation at $95^{\circ} \mathrm{C}$ for $5 \mathrm{~min}$, then 45 cycles at $95^{\circ} \mathrm{C}$ for $15 \mathrm{sec}$, $60^{\circ} \mathrm{C}$ for $15 \mathrm{sec}$, and $72^{\circ} \mathrm{C}$ for $15 \mathrm{sec}$. The comparative $\mathrm{C}_{\mathrm{T}}$ method $\left(\Delta \Delta \mathrm{C}_{\mathrm{T}}\right)$ was used for quantification and was calculated as follows: $\Delta \mathrm{C}_{\mathrm{T}}=\mathrm{C}_{\mathrm{T}}$ (target gene) - $\mathrm{C}_{\mathrm{T}}$ (reference gene), and $\Delta \Delta \mathrm{C}_{\mathrm{T}}=\Delta \mathrm{C}_{\mathrm{T}}$ (sample) $-\Delta \mathrm{C}_{\mathrm{T}}$ (control). Relative quantification was derived by $2^{-\Delta \Delta \mathrm{Cq}}$.

Southern blot analysis of the terminal restriction fragment. Genomic DNA was isolated using standard phenol-chloroform extraction following proteinase $\mathrm{K}$ (Invitrogen) treatment, and digested with HinfI overnight at $37^{\circ} \mathrm{C}$. HinfI-digested DNA $(5 \mu \mathrm{g})$ was fractionated on an $0.8 \%$ agarose gel and transferred onto a nylon membrane using the upward capillary method. Hybridization was performed with a 3 '-end

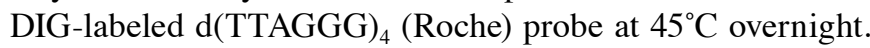
The membrane was washed and hybridization was detected as recommended by the manufacturer (Roche). Telomere length 
A

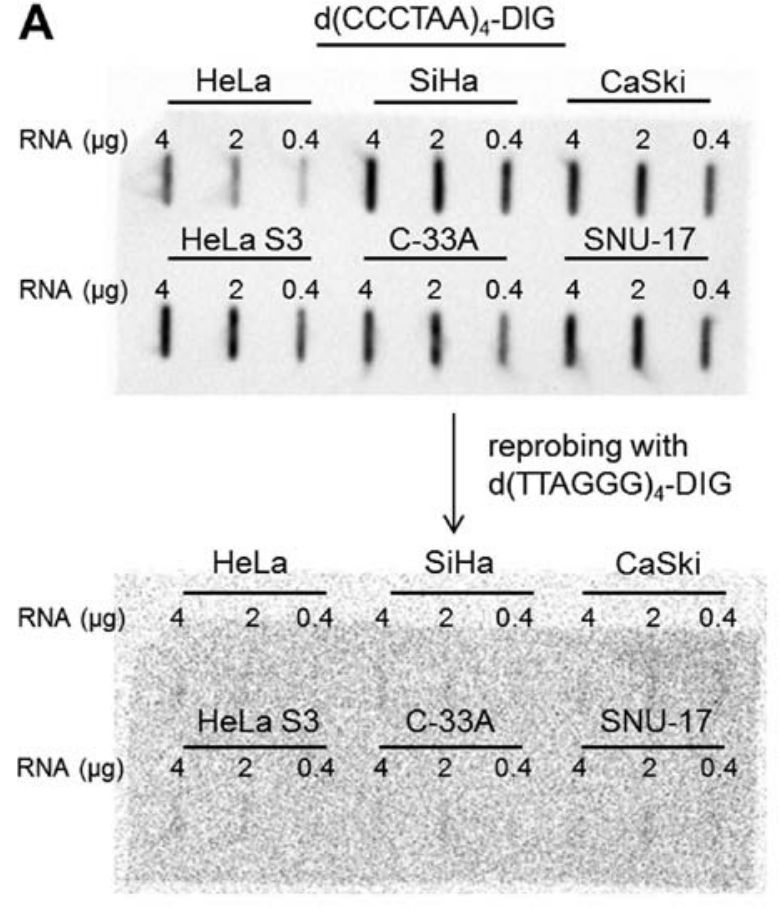

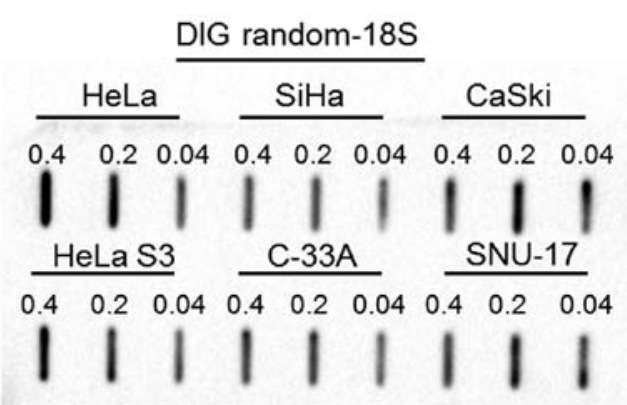

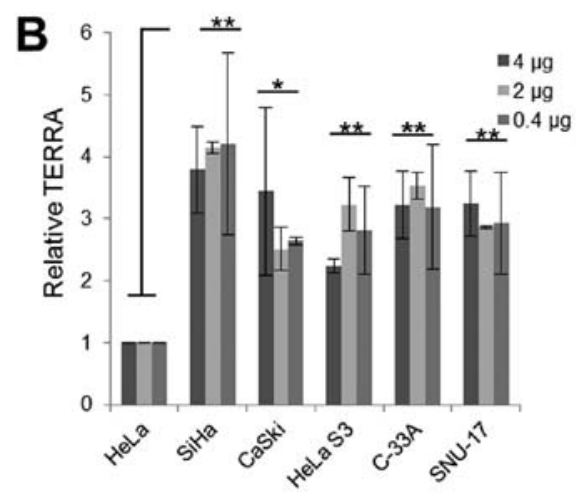

C

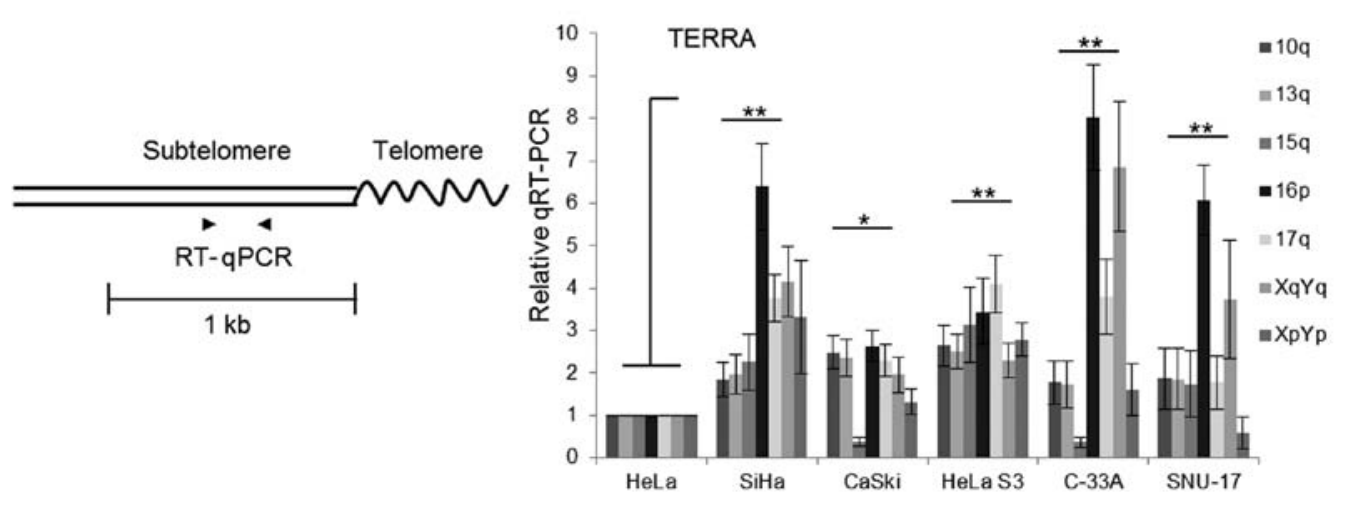

Figure 1. Expression of telomeric repeat-containing RNA (TERRA) in cervical cancer cells. (A) Slot-blot analysis of TERRA in 6 cervical cancer cell lines Total RNA extracted from cells at $90 \%$ confluency was slot-blotted and hybridized with a DIG-labeled d(CCCTAA) ${ }_{4}$ probe for TERRA or with a DIG-random-primed $18 \mathrm{~S}$ rRNA probe as an internal control. The blot used for TERRA detection was rinsed and reprobed with a DIG-labeled d(TTAGGG) ${ }_{4}$ probe. The amount of total RNA immobilized in each slot is indicated. (B) Quantification of TERRA in (A). TERRA level normalized by 18S rRNA was quantified as a ratio relative to that of HeLa cells. Error bars were derived from 2 independent assays ( $\mathrm{P}<0.05,{ }^{* *} \mathrm{P}<0.005$ by t-test). (C) RT-qPCR of TERRA in cervical cancer cells. Scheme of a subtelomere and telomere (left panel). Arrowheads indicate the positions of the primers used for RT-qPCR. TERRA level was measured by RT-qPCR (right panel). Relative RT-qPCR represents the value calculated using the $\Delta \Delta \mathrm{Cq}$ method relative to HeLa cells and $\beta$-actin. Error bars were derived from 3 independent experiments (means $\pm \mathrm{SD} ;{ }^{*} \mathrm{P}<0.05,{ }^{* *} \mathrm{P}<0.005$ by t-test).

was measured as the highest peak of the signal intensity using Image Lab software (Bio-Rad, Hercules, CA, USA).

Statistical analysis. Statistical analysis was assessed using a Student's t-test and Spearman's correlation as deemed appropriate. The level of statistical significance was set at $\mathrm{P}<0.05$.

\section{Results and Discussion}

Variable TERRA levels in cervicalcancercells. Slot-blotanalysis was performed to monitor the TERRA levels in the 6 cervical cancer cells, HeLa, SiHa, CaSki, HeLa S3 (a clonal derivative of the parent HeLa line), C-33A and SNU-17. Total RNA was blotted onto a membrane and hybridization was followed with a strand-specific TERRA probe, d(CCCTAA) ${ }_{4}$-DIG (Fig. 1A).
Hybridization with the d(CCCTAA $)_{4}$-DIG probes was quantified as a ratio relative to the level measured in HeLa cells following normalization by $18 \mathrm{~S}$ rRNA (Fig. 1B). The hybridization signal was approximately 2- to 4-fold greater in the $\mathrm{SiHa}$, CaSki, HeLa S3, C-33A and SNU-17 cells than in the HeLa cells (Fig. 1A and 1B). The blot used for TERRA detection was stripped and reprobed with a DIG-labeled d(TTAGGG) probe identical to the TERRA repeat sequences, and this hybridization resulted in weak signals (Fig. 1A). This indicated that RNAs with UUAGGG repeats, which are considered to be TERRA, are abundant in cervical cancer cells, whereas CCCUAA-containing RNA molecules exist at very low levels.

Slot blotting is a tool which is used to monitor the UUAGGG repeat content rather than the number of TERRA molecules (23). Thus, the TERRA level was also assessed in subtelomeres using 
chromosome-specific RT-qPCR with primers matching the different chromosome arms (Fig. 1C and Table I). Note that the primer pairs used in this study amplify DNA fragments from more than one subtelomere due to the repetitive nature of subtelomeric DNA $(7,13,24-27)$. TERRA for almost all subtelomeres tested in this study was more abundant in 5 of the cell lines compared with the HeLa cells (Fig. 1C). TERRA transcription at specific chromosome ends appeared to behave differently from that in the independent chromosome ends in some cells. For example, 16p TERRA was detected at a high level in the SiHa, C-33A and SNU-17 cells, and 15q TERRA was detected at a low level in the CaSki and C-33A cells. Overall, the results of RT-qPCR were consistent with those of slot blotting.

TERRA stability in cervical cancer cells. We wondered whether the variable TERRA levels in cervical cancer cells reflect different degrees of RNA stability. To assess this possibility, we measured the TERRA half-life by treating the cells with Act D to block transcription. RT-qPCR was used to monitor TERRA levels derived from chromosomes $10 \mathrm{q}$ and $17 \mathrm{q}$ over time (Fig. 2, left panels). The cell lines tested in this study were viable under these conditions. PinX1, which encodes a telomere-binding protein (6), $\beta$-actin and U1 small nuclear RNA (snRNA) were included in the analysis (Fig. 2). Act D treatment reduced the PinX1 mRNA levels in all cells to a half-life of 2-3 $\mathrm{h}$ in the SiHa, HeLa S3 and C-33A cells, and 4-5 h in the HeLa, CaSki and SNU-17 cells (Fig. 2, middle panels and Table II). These results confirmed that Act D inhibited RNAPII function effectively. The $\beta$-actin transcript was stable in the SiHa, CaSki, C-33A and SNU-17 cells with a half-life of $>8 \mathrm{~h}$; the half-life was shorter in the HeLa and HeLa S3 cells, approximately 5 h (Fig. 2, middle panels and Table II). U1 snRNA is transcribed by RNAPII and is known to be stable and abundant in human cells $(28,29)$. This RNA was stably maintained in all cells tested with a half-life of $>8 \mathrm{~h}$ (Fig. 2, right panels and Table II). U1 snRNA expression was slightly increased at later time points in almost all cell lines; in particular, a gradual increase was observed in the SiHa cells (Fig. 2 , right panels). $\beta$-actin and U1 snRNA were initially included as internal controls; however, the level of these gene transcripts changed upon Act D treatment in some cells. Therefore, the RNA levels in the Act D-treated cells were quantified as a relative value against that of the untreated cells without normalization (Fig. 2).

Our RT-qPCR experiments revealed that the levels of TERRA derived from $10 \mathrm{q}$ and $17 \mathrm{q}$ decreased upon Act $\mathrm{D}$ treatment in HeLa cells (Fig. 2, left panels). The half-life of TERRA was approximately $4 \mathrm{~h}$ in the HeLa cells (Fig. 2 and Table II), which is similar to the approximate $3 \mathrm{~h}$ value measured using Act D in a northern blot analysis procedure reported previously (14). Unlike the HeLa cells, the other 5 cell lines did not exhibit a decrease in TERRA levels upon Act D treatment (Fig. 2, left panels). The half-life of TERRA was maintained at $>8 \mathrm{~h}$ in the $\mathrm{SiHa}$, CaSki and SNU-17 cells. Similar to the results of RT-qPCR, slot blotting of the total RNA assessed over time with a TERRA-specific probe revealed that TERRA was degraded more rapidly in the HeLa cells than in the SiHa, CaSki and SNU-17 cells (Fig. 3). It has been reported that a small fraction of TERRA contains a poly(A) tail at the 3 '-end in HeLa (14). This may explain why TERRA has a short half-life in these cells. Although highly speculative, the other
Table II. Summary of the half-life of TERRA, PinX1, $\beta$-actin and $\mathrm{U} 1$ snRNA, and telomere length in cervical cancer cells.

\begin{tabular}{llcccc}
\hline & \multicolumn{5}{c}{$t_{1 / 2}$} \\
Cell line & TERRA & PinX1 & $\beta$-actin & U1 snRNA & $\begin{array}{c}\text { Telomere length } \\
\text { mean } \pm \text { SD (kb) }\end{array}$ \\
\cline { 2 - 5 } HeLa & $10 \mathrm{q}, 4 \mathrm{~h}$ & $5 \mathrm{~h}$ & $5 \mathrm{~h}$ & $>8 \mathrm{~h}$ & $5.6 \pm 0.72$ \\
& $17 \mathrm{q}, 4 \mathrm{~h}$ & & & & \\
SiHa & $10 \mathrm{q},>8 \mathrm{~h}$ & $2 \mathrm{~h}$ & $>8 \mathrm{~h}$ & $>8 \mathrm{~h}$ & $9.5 \pm 0.87$ \\
& $17 \mathrm{q},>2 \mathrm{~h}$ & & & & \\
CaSki & $10 \mathrm{q},>8 \mathrm{~h}$ & $4 \mathrm{~h}$ & $>8 \mathrm{~h}$ & $>8 \mathrm{~h}$ & $5.0 \pm 0.63$ \\
& $17 \mathrm{q},>8 \mathrm{~h}$ & & & & \\
HeLa S3 & $10 \mathrm{q},>8 \mathrm{~h}$ & $3 \mathrm{~h}$ & $5 \mathrm{~h}$ & $>8 \mathrm{~h}$ & $10.4 \pm 1.03$ \\
& $17 \mathrm{q},>8 \mathrm{~h}$ & & & & \\
C-33A & $10 \mathrm{q},>8 \mathrm{~h}$ & $2 \mathrm{~h}$ & $>8 \mathrm{~h}$ & $>8 \mathrm{~h}$ & $4.5 \pm 1.47$ \\
& $17 \mathrm{q},>8 \mathrm{~h}$ & & & & \\
SNU-17 & $10 \mathrm{q},>8 \mathrm{~h}$ & $4 \mathrm{~h}$ & $>8 \mathrm{~h}$ & $>8 \mathrm{~h}$ & $5.9 \pm 0.52$ \\
& $17 \mathrm{q},>8 \mathrm{~h}$ & & & & \\
\hline
\end{tabular}

$t_{1 / 2}$, approximate half-life value (Fig. 2).

cervical cancer cells may maintain poly(A)+ TERRA as the predominant form. However, we cannot exclude the possibility that TERRA is transcribed by other RNA polymerases; for instance, RNAPI- or III-mediated TERRA transcription was less sensitive under our experimental condition in the cells, which may have allowed the persistent synthesis of TERRA.

Our RT-qPCR experiments revealed a gradual increase in TERRA levels, particularly 10q in HeLa S3 and 10q and 17q in C-33A cells, upon Act D treatment' (Fig. 2, left panels). We wondered whether this phenomenon would be detected by slot blotting. The results of slot blotting revealed that the UUAGGG signals increased in these cells upon Act D treatment (Fig. 3), indicating that the induced RNA detected by RT-qPCR was derived from telomeric RNA. The mechanism responsible for the increased TERRA accumulation in the presence of Act D remains unknown. TERRA may be released from RNA degradation cycles in these particular cells. It would be interesting to test whether newly synthesized RNA accounts for the increased TERRA. Collectively, these finding suggest that TERRA was less abundant and was degraded more rapidly in the HeLa cells, but was abundant and stable in the other 5 cell lines.

Telomere length and expression of telomere genes in cervical cancer cells. Telomere length was measured using Southern blot analysis of terminal restriction fragment lengths. The average telomere length was determined as the highest peak of the signal intensity. The telomeres were significantly longer in the SiHa and HeLa S3 cells than in the other 4 cell lines (Fig. 4A and Table II). To determine whether telomere length is related to TERRA expression in cervical cells, the TERRA levels measured by RT-qPCR were plotted against telomere length. Telomere length did not correlate significantly with the TERRA level (Fig. 4B, $\mathrm{P}=0.645$ ). If anything, there was a tendency for cells with long telomeres to express higher levels of TERRA, and this was somewhat consistent with 

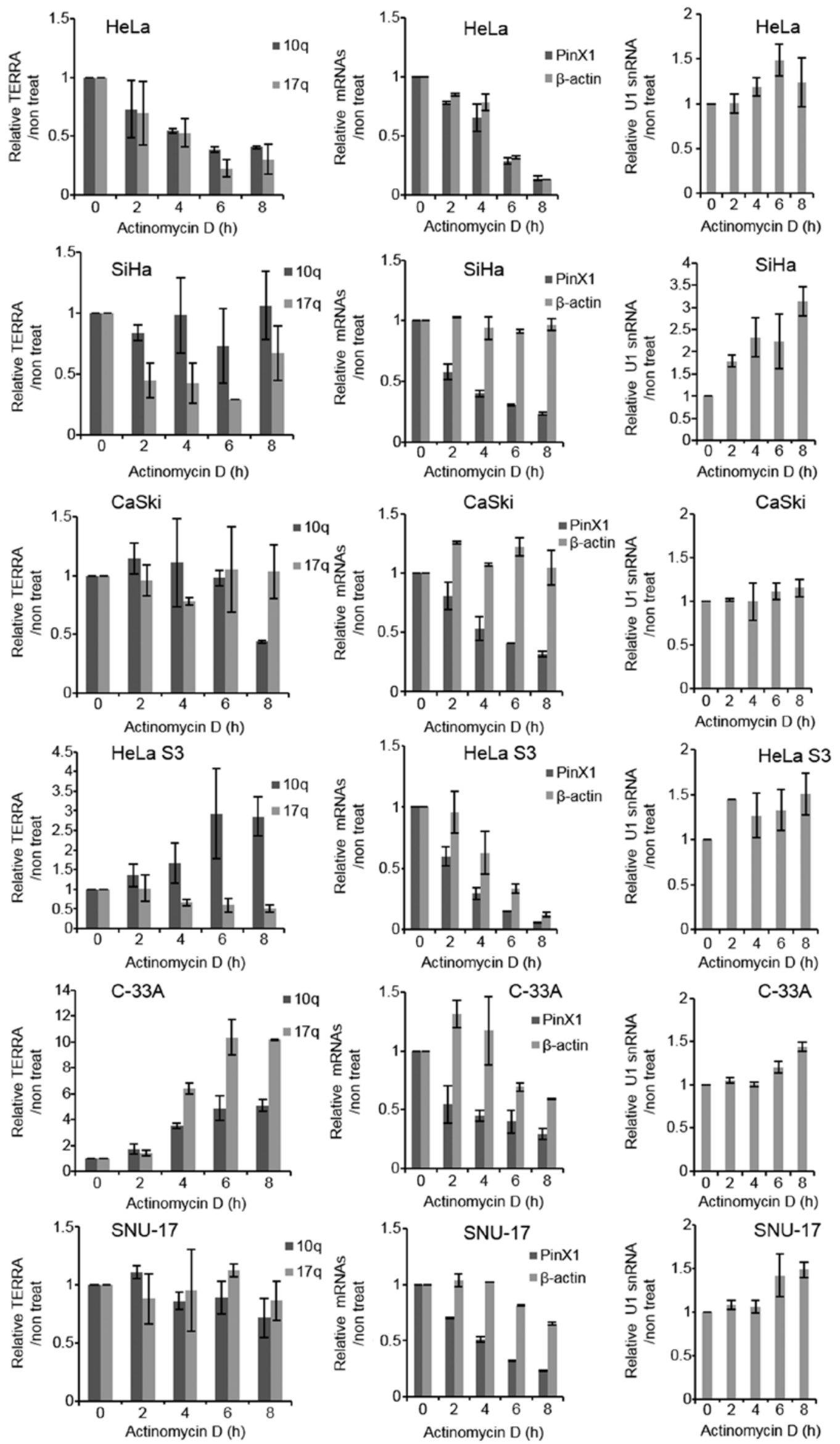

Figure 2. Stability of telomeric repeat-containing RNA (TERRA) in six cervical cancer cell lines. Total RNA was extracted from the cells treated with actinomycin D (Act D) at $5 \mu \mathrm{g} / \mathrm{ml}$ for the indicated periods of time. RT-qPCR was performed to detect TERRA from 10q and 17q (left panels), mRNA levels of PinX1 and $\beta$-actin (middle panels), and U1 snRNA (right panels). RNA level was quantified as a ratio relative to that of untreated (0 h) cells. Error bars were derived from 3 independent experiments (means $\pm \mathrm{SD}$ ). 
HeLa

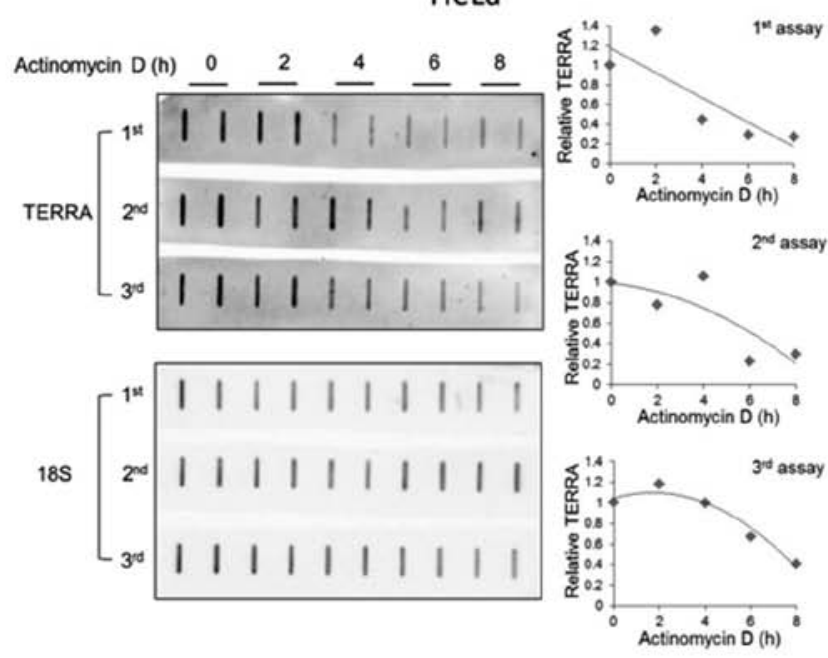

HeLaS3
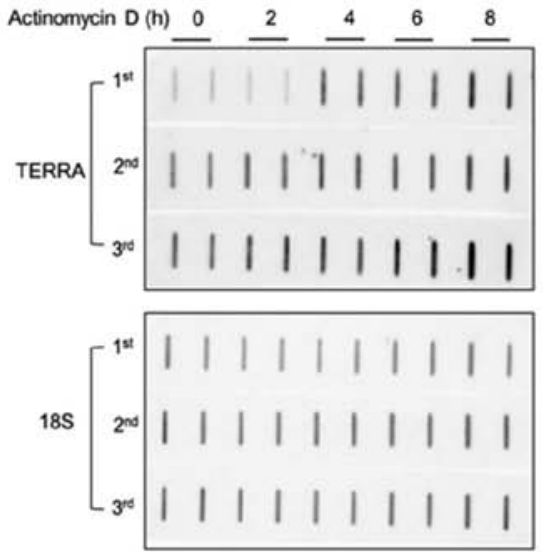

$\mathrm{SiHa}$

C-33A
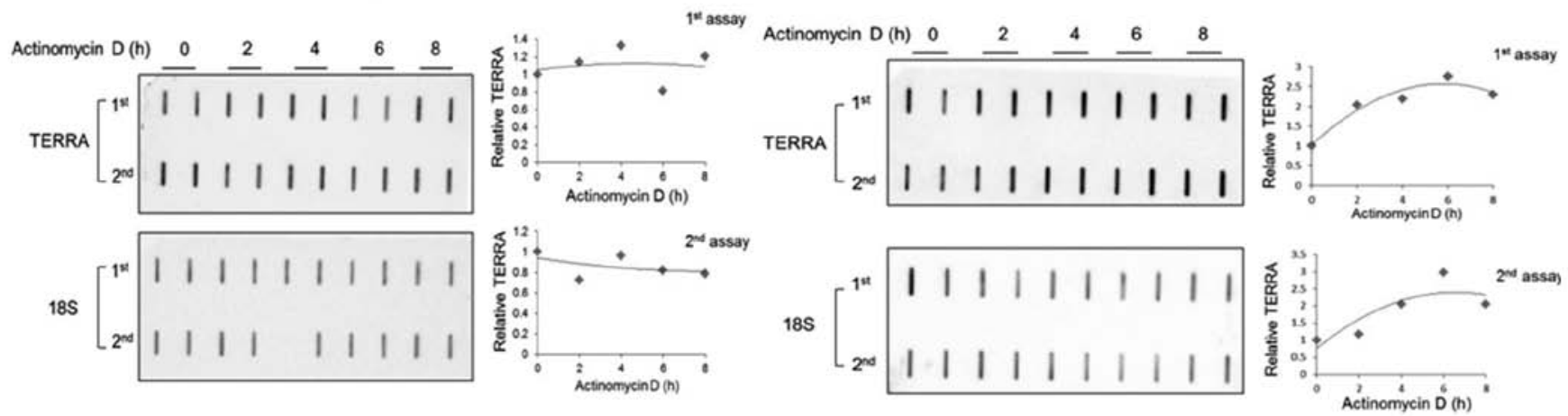

CaSki

SNU-17
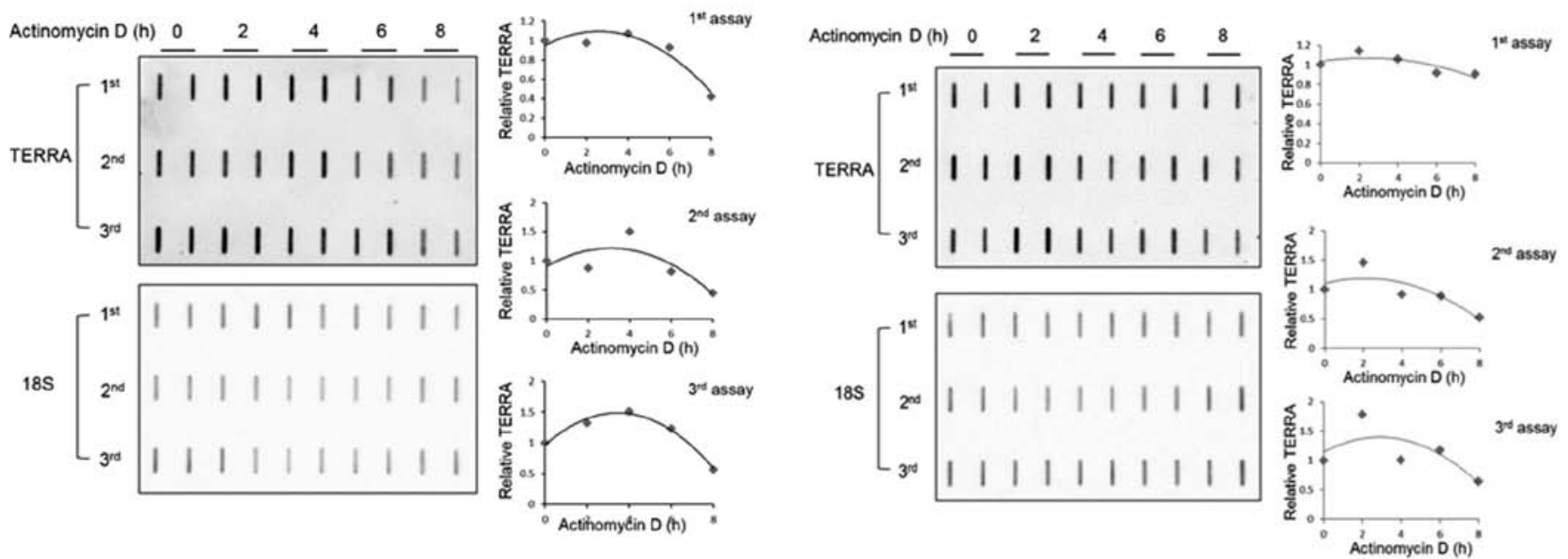

Figure 3. Slot-blot analysis of telomeric repeat-containing RNA (TERRA) RNA from 6 cervical cancer cells over the indicated time course. Total RNA was extracted from the cells treated with actimomycin D at indicated periods of time, and $5 \mu \mathrm{g}$ of RNA were loaded for TERRA and 0.4 $\mu \mathrm{g}$ for $18 \mathrm{~S}$ rRNA per slot.

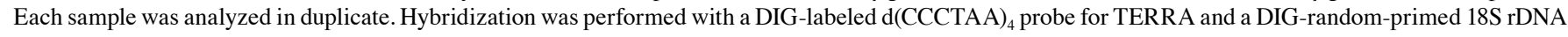
probe for $18 \mathrm{~S}$ rRNA as an internal control. Two or three independent experiments were performed. TERRA levels normalized to $18 \mathrm{~S}$ rRNA were quantified as a ratio relative to $0 \mathrm{~h}$ (graphs on the right).

the results reported previously (30). This tendency was more evident after excluding from the analysis TERRA expression at $16 \mathrm{p}$, which was particularly high compared with the expression at other chromosome ends $(\mathrm{P}=0.015)$ (Fig. 4B, graph on the right). Nonetheless, the number of cell lines tested in this study may be insufficient to reveal an association. Collectively, there was a lack of correlation between telomere length and TERRA transcription in the cervical cancer cells. The functional interaction between these two parameters may depend on the cell type, as noted previously (21). 

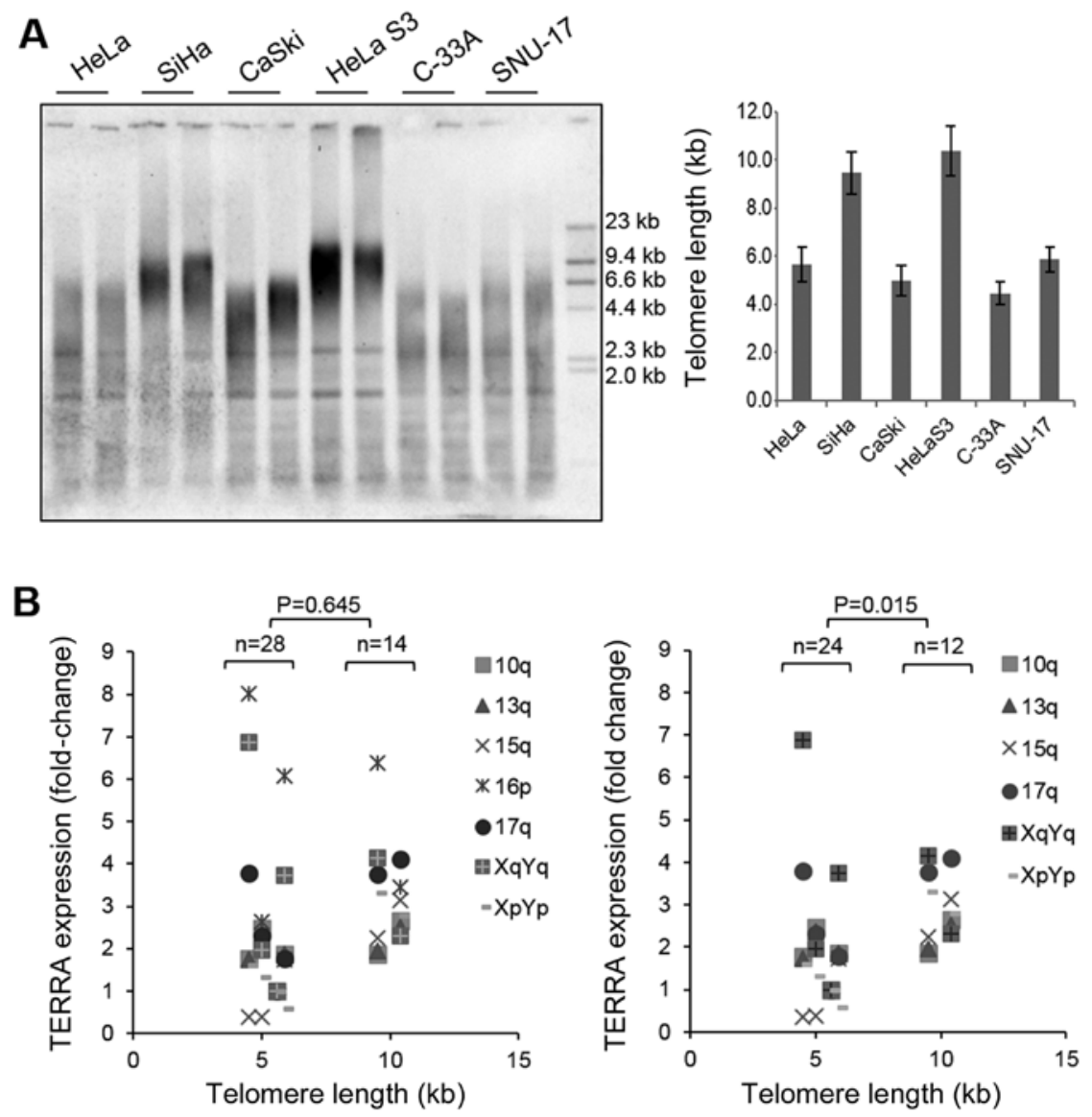

Figure 4. Lack of correlation between telomere length and telomeric repeat-containing RNA (TERRA) expression in cervical cancer cells. (A) Southern blot of terminal restriction fragments in cervical cancer cells. Genomic DNA isolated from 2 independent cultures was digested with HinfI, transferred to a nylon membrane, and hybridized with a DIG-labeled d(TTAGGG) $)_{4}$ probe. Telomere length was determined by the highest peak signal. Error bars were derived from two measurements (graph on right). (B) Scatter plot of telomere length vs. TERRA expression. Telomere length and TERRA expression determined by RT-qPCR were plotted (graph on the left). The same analysis without TERRA at 16p is shown on the right. The data were analyzed using the Student's t-test.
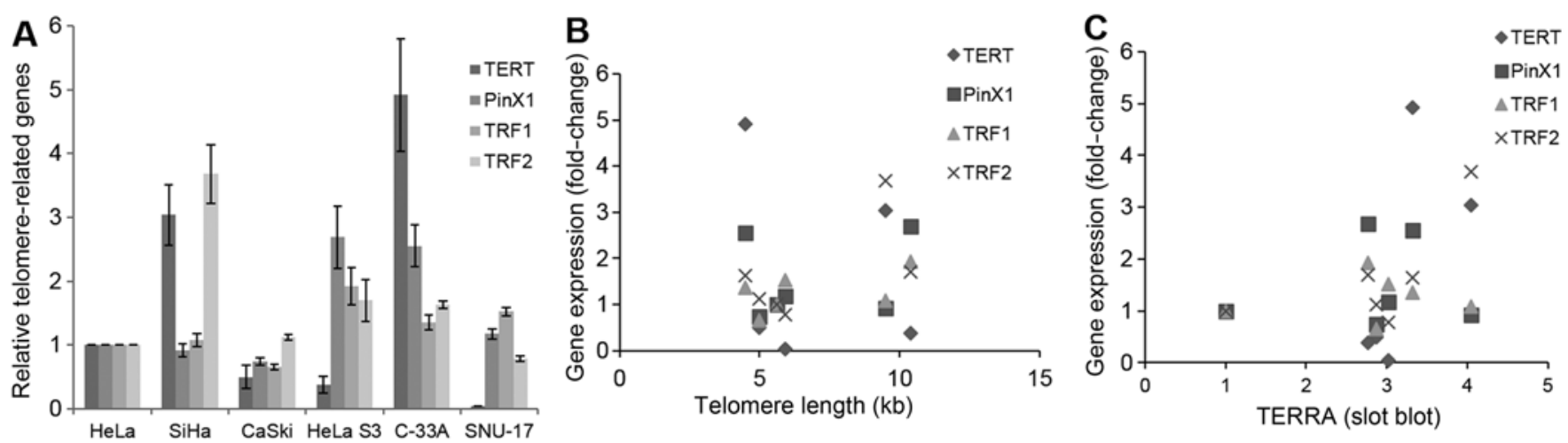

Figure 5. Expression of telomere genes in cervical cancer cells. (A) RT-qPCR of telomere-related genes in cervical cancer cells. First-strand cDNA was synthesized by random hexamer priming, RT-qPCR was performed with SYBR-Green reagents, and $\beta$-actin was used as a control. Relative RT-PCR represents the values calculated by the comparative ( $\Delta \Delta \mathrm{CT}$ ) method relative to the values for $\beta$-actin and HeLa cells. Error bars were derived from two independent assays. (B) Scatter plot of telomere length vs. the levels of telomere genes. Telomere length measured by Southern blotting and telomere gene levels determined by RT-qPCR are plotted. (C) Scatter plot of telomeric repeat-containing RNA (TERRA) level vs. levels of telomere genes. TERRA levels measured by slot blotting and levels of telomere genes are plotted. (B and C) P-values by Spearman correlation analysis were not indicated as they were much higher than 0.05 .

The shelterin proteins, telomere repeat-binding factor 1 (TRF1) and TRF2, are important for recruiting other shelterin proteins to telomeres and negatively regulate telomere length (6). PinX1, a TRF1-interacting protein, inhibits telomerase activity and regulates telomere length in a negative manner (31). TERT, a catalytic component of telomerase, acts as a positive regulator of telomere length (32). It has recently been reported that TRF1 and TRF2 associate functionally with TERRA transcription; for instance, the depletion of TRF1 or TRF2 leads to the accumulation of TERRA (33). In this study, we measured the mRNA levels of TERT, PinX1, TRF1 and TRF2 (Fig. 5A), and we examined whether these are related to 
telomere length and TERRA level. The mRNA levels of none of these genes correlated significantly with telomere length or TERRA level in cervical cancer cells (Fig. 5B and 5C).

In conclusion, TERRA abundance and stability vary between types of cervical cancer cells. TERRA is degraded rapidly in HeLa cells, but is maintained stably in other cervical cancer cell lines. TERRA abundance is associated with the stability of the RNA in cervical cancer cells; however, there was a lack of correlation between the TERRA level and telomere length. Additional studies are warranted to explore the mechanisms that regulate TERRA steady-state levels.

\section{Acknowledgements}

This study was supported by the Basic Science Research Program through the the National Research Foundation of Korea (NRF) funded by the Ministry of Education (nos. 2010-0008254, 2014R1A1A2054542 to B.-K.O.) and funded by the Ministry of Science, ICT and Future Planning (no. 2011-0015638 to B.-K.O.) and by the Hanyang University (no. 201200000002989 to J.S.C.).

\section{References}

1. Greider CW and Blackburn EH: Identification of a specific telomere terminal transferase activity in Tetrahymena extracts. Cell 43: 405-413, 1985.

2. de Lange T: Shelterin: The protein complex that shapes and safeguards human telomeres. Genes Dev 19: 2100-2110, 2005.

3. Shay JW, Zou Y, Hiyama E and Wright WE: Telomerase and cancer. Hum Mol Genet 10: 677-685, 2001.

4. Bodnar AG, Ouellette M, Frolkis M, Holt SE, Chiu CP, Morin GB, Harley CB, Shay JW, Lichtsteiner S and Wright WE: Extension of life-span by introduction of telomerase into normal human cells. Science 279: 349-352, 1998

5. Nakayama J, Tahara H, Tahara E, Saito M, Ito K, Nakamura H, Nakanishi T, Tahara E, Ide T and Ishikawa F: Telomerase activation by hTRT in human normal fibroblasts and hepatocellular carcinomas. Nat Genet 18: 65-68, 1998.

6. Palm $\mathrm{W}$ and de Lange $\mathrm{T}$ : How shelterin protects mammalian telomeres. Annu Rev Genet 42: 301-334, 2008.

7. Azzalin CM, Reichenbach P,Khoriauli L, Giulotto E and Lingner J Telomeric repeat containing RNA and RNA surveillance factors at mammalian chromosome ends. Science 318: 798-801, 2007.

8. Schoeftner S and Blasco MA: Developmentally regulated transcription of mammalian telomeres by DNA-dependent RNA polymerase II. Nat Cell Biol 10: 228-236, 2008.

9. Luke B, Panza A, Redon S, Iglesias N, Li Z and Lingner J: The Rat1p 5' to 3' exonuclease degrades telomeric repeat-containing RNA and promotes telomere elongation in Saccharomyces cerevisiae. Mol Cell 32: 465-477, 2008.

10. Vrbsky J, Akimcheva S, Watson JM, Turner TL, Daxinger L, Vyskot B, Aufsatz W and Riha K: siRNA-mediated methylation of Arabidopsis telomeres. PLoS Genet 6: e1000986, 2010.

11. Bah A, Wischnewski H, Shchepachev V and Azzalin CM: The telomeric transcriptome of Schizosaccharomyces pombe. Nucleic Acids Res 40: 2995-3005, 2012.

12. Nergadze SG, Farnung BO, Wischnewski H, Khoriauli L, Vitelli V, Chawla R, Giulotto E and Azzalin CM: CpG-island promoters drive transcription of human telomeres. RNA 15: 2186-2194, 2009.

13. Arnoult N, Van Beneden A and Decottignies A: Telomere length regulates TERRA levels through increased trimethylation of telomeric H3K9 and HP1 $\alpha$. Nat Struct Mol Biol 19: 948-956, 2012.
14. Porro A, Feuerhahn S, Reichenbach P and Lingner J: Molecular dissection of telomeric repeat-containing RNA biogenesis unveils the presence of distinct and multiple regulatory pathways. Mol Cell Biol 30: 4808-4817, 2010.

15. Deng Z, Wang Z, Xiang C, Molczan A, Baubet V, ConejoGarcia J, Xu X, Lieberman PM and Dahmane N: Formation of telomeric repeat-containing RNA (TERRA) foci in highly proliferating mouse cerebellar neuronal progenitors and medulloblastoma. J Cell Sci 125: 4383-4394, 2012.

16. Azzalin CM and Lingner J: Telomere functions grounding on TERRA firma. Trends Cell Biol 25: 29-36, 2015.

17. Yehezkel S, Segev Y, Viegas-Péquignot E, Skorecki K and Selig S: Hypomethylation of subtelomeric regions in ICF syndrome is associated with abnormally short telomeres and enhanced transcription from telomeric regions. Hum Mol Genet 17: 2776-2789, 2008.

18. Pfeiffer $V$ and Lingner J: TERRA promotes telomere shortening through exonuclease 1-mediated resection of chromosome ends. PLoS Genet 8: e1002747, 2012.

19. Redon S, Reichenbach P and Lingner J: The non-coding RNA TERRA is a natural ligand and direct inhibitor of human telomerase. Nucleic Acids Res 38: 5797-5806, 2010.

20. Iglesias N, Redon S, Pfeiffer V, Dees M, Lingner J and Luke B: Subtelomeric repetitive elements determine TERRA regulation by Rap1/Rif and Rap1/Sir complexes in yeast. EMBO Rep 12: 587-593, 2011.

21. Farnung BO, Brun CM, Arora R, Lorenzi LE and Azzalin CM: Telomerase efficiently elongates highly transcribing telomeres in human cancer cells. PLoS One 7: e35714, 2012.

22. Smirnova A, Gamba R, Khoriauli L, Vitelli V, Nergadze SG and Giulotto E: TERRA expression levels do not correlate with telomere length and radiation sensitivity in human cancer cell lines. Front Oncol 3: 115, 2013.

23. Van Beneden A, Arnoult N and Decottignies A: Telomeric RNA expression: Length matters. Front Oncol 3: 178, 2013.

24. Deng Z, Wang Z, Stong N, Plasschaert R, Moczan A, Chen HS Hu S, Wikramasinghe P, Davuluri RV, Bartolomei MS, et al: A role for CTCF and cohesin in subtelomere chromatin organization, TERRA transcription, and telomere end protection. EMBO J 31: 4165-4178, 2012

25. Riethman HC, Xiang Z, Paul S, Morse E, Hu XL, Flint J, Chi HC, Grady DL and Moyzis RK: Integration of telomere sequences with the draft human genome sequence. Nature 409: 948-951, 2001.

26. Riethman H, Ambrosini A, Castaneda C, Finklestein J, Hu XL, Mudunuri U, Paul S and Wei J: Mapping and initial analysis of human subtelomeric sequence assemblies. Genome Res 14: $18-28,2004$.

27. Ambrosini A, Paul S, Hu S and Riethman H: Human subtelomeric duplicon structure and organization. Genome Biol 8: R151, 2007.

28. Ro-Choi TS, Raj NB, Pike LM and Busch H: Effects of alphaamanitin, cycloheximide, and thioacetamide on low molecular weight nuclear RNA. Biochemistry 15: 3823-3828, 1976.

29. Noonberg SB, Scott GK and Benz CC: Evidence of posttranscriptional regulation of U6 small nuclear RNA. J Biol Chem 271: 10477-10481, 1996.

30. Vitelli V, Falvo P, Khoriauli L, Smirnova A, Gamba R, Santagostino M, Nergadze SG and Giulotto E: More on the lack of correlation between terra expression and telomere length. Front Oncol 3: 245, 2013.

31. Zhou XZ and Lu KP: The Pin2/TRF1-interacting protein PinX1 is a potent telomerase inhibitor. Cell 107: 347-359, 2001

32. Autexier $\mathrm{C}$ and Lue NF: The structure and function of telomerase reverse transcriptase. Annu Rev Biochem 75: 493-517, 2006.

33. Porro A, Feuerhahn S, Delafontaine J, Riethman H, Rougemont J and Lingner J: Functional characterization of the TERRA transcriptome at damaged telomeres. Nat Commun 5: 5379, 2014.

34. Scheibe M, Arnoult N, Kappei D, Buchholz F, Decottignies A, Butter F and Mann M: Quantitative interaction screen of telomeric repeat-containing RNA reveals novel TERRA regulators. Genome Res 23: 2149-2157, 2013. 